\title{
Low Cycle Fatigue Fracture Properties of 06Cr19Ni10 Steel under Controlled Stress
}

\author{
LIU Jianhui \\ Northwestern Polytechnical University \\ School of aeronautics \\ Xi'an China 710072 \\ liujianhui2010@163.com
}

\section{WEI Yaobing}

Lanzhou University of Technology

School of mechanical \& electronical engineering

Lanzhou China 730050

\begin{abstract}
The low cycle fatigue fracture properties are studied based on notch and smooth specimens fatigue tests in this work. The relationship between strain and life and that between stress and energy are observated under different load conditions. The $\sigma-\mathrm{N}$ curve in double logarithmic coordinates for different notch depth and angle is found out by testing specimens. The results show that the greater stress and the deeper incision, the shorter the life of the specimen, but there is no effect on specimen life when incision angle located at $30^{\circ}-60^{\circ}$. Observations of fracture surfaces show that fatigue cracks source of point and fracture morphology are closely related to stress amplitude.
\end{abstract}

Keywords- $\sigma-N$ curve; fatigue test; low cycle fatigue; the conditions fatigue limit; fracture morphology

\section{INTRODUCTION}

$06 \mathrm{Cr} 19 \mathrm{Ni10steel}$ is the most extensively applied chrome-nickel stainless steel, which has high quality of corrosion resistance, heat resistance, cold strength and mechanical property. It is widely used to make facilities and machine parts which require high combination property in machinery and aerospace areas[1-2]. Most of facilities are made into oil and gas lines and pressure vessels etc., and most of which are applied in special working conditions[3]. Most of their static strength can satisfy requirements, so the research on low cycle fatigue fracture properties is carried out for reality needs. Fatigue fracture of facilities made by $06 \mathrm{Cr} 19 \mathrm{Ni} 10$ steel results in catastrophic accidents sometimes[4]. Because 06Cr19Ni10 steel is extensively applied in engineering, the further research on its fatigue fracture properties is still needed. For a more accurate knowledge about fatigue fracture characteristics of $06 \mathrm{Cr} 19 \mathrm{Ni10}$ steel, the fatigue tests of $06 \mathrm{Cr} 19 \mathrm{Ni10}$ steel sample must be carried out except for simulation analysis of it. This paper focuses on studying of the low cycle fatigue fracture characteristics under controlled stress based on smooth specimen and incision specimen[5-6]. Theoretical data will be concluded for the engineering practice and structure life estimation.

\author{
WANG Shengnan \\ Northwestern Polytechnical University \\ School of aeronautics \\ Xi'an China 710072 \\ wangshna@nwpu.edu.cn \\ MAO Jiabing \\ Northwestern Polytechnical University \\ School of aeronautics \\ Xi'an China 710072
}

\section{CONTENT AND METHOD}

\section{A. Test Equipment and Material}

An Instron Servohydraulic frame was used for the fatigue tests. The testing system is equipped with the Instron 8800 electronic control, computer control, and data acquisition. The load cell of the testing system has a capacity of $\pm 100 \mathrm{KN}$ in axial load. The material under investigation was $06 \mathrm{Cr} 19 \mathrm{Ni} 10$ steel, a kind of widely used material in engineering. The testing specimens were taken from a hot rolled bar with a diameter of $\Phi 45 \mathrm{~mm}$. The diameter of the gauge section was $11 \mathrm{~mm}$ and length was $20 \mathrm{~mm}$. The static strength test was carried out on fatigue test machine and the sample cracked when the load was $56.8 \mathrm{KN}$ and the length of it was $28 \mathrm{~mm}$. The chemical composition and property of the sample were listed in Table 1. All indexes satisfy property requirement of $06 \mathrm{Cr} 19 \mathrm{Ni} 10$ steel and the data will be the reference of the parameter of fatigue test.

TABLE I. CHEMICAL COMPOSITION AND PROPERTIES OF 06CR19NI10 STEEL

\begin{tabular}{|c|c|c|c|c|}
\hline $\boldsymbol{C} \%$ & $\mathbf{M n} \%$ & $\boldsymbol{S} \%$ & $\boldsymbol{P} \%$ & $\boldsymbol{S i} \%$ \\
\hline 0.054 & 0.79 & 0.002 & 0.034 & 0.42 \\
\hline $\boldsymbol{C r} \%$ & $\boldsymbol{N i \%}$ & $\boldsymbol{\sigma}_{b}(\mathbf{M P a})$ & $\boldsymbol{\delta} \%$ & \\
\hline 17.27 & 8.14 & 577 & 45 & \\
\hline
\end{tabular}

\section{B. Sample Preparation}

The preparation of the sample was based on national standards of ASTME606-92, GB/T15248-94 and GB307582. The shape, size and incision parameters of sample were shown in Fig. 1 and Fig. 2. For more convenient of the observation, the cracked sample was cut into cylinders of $1 \mathrm{~cm}$ by linear cutting and the amplified fracture surface was observed in different multiples on scanning electron microscope. 


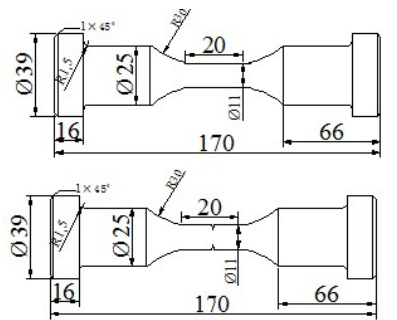

Figue 1. Test sample

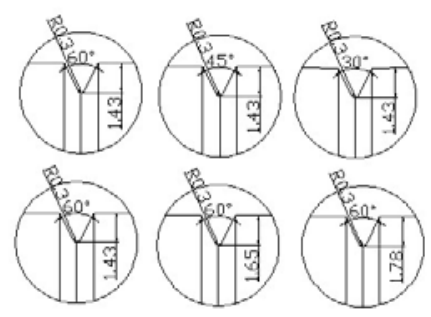

Figue 2. Incision parameters

\section{Test conditions}

Axial reversed tension-compression load was used in fatigue tests, whose stress ratio equaled to -1 and frequency equaled to $10 \mathrm{~Hz}$. In the tests the load control mode referred to stress control and load waveform was pyramidal wave. Tests were carried out in $20^{\circ} \mathrm{C}$.

\section{TEST RESULTS AND ANALYSIS OF SMOOTH SPECIMEN}

\section{A. The influence of stress amplitude on life}

Stress in tests was measured as nominal stress and the tests were conducted out three times in each level of stress. The results were shown in Table. 2.

TABLE II. LIFE UNDER DIFFERENT LOAD

\begin{tabular}{|c|c|c|c|}
\hline Stress $(\boldsymbol{M P a})$ & first(cycles) & second(cycles) & third(cycles) \\
\hline $329\left(\sigma_{1}\right)$ & 2066 & 2270 & 2106 \\
\hline $318\left(\sigma_{2}\right)$ & 3184 & 1311 & 2044 \\
\hline $307\left(\sigma_{3}\right)$ & 4087 & 3391 & 3339 \\
\hline $296\left(\sigma_{4}\right)$ & 5425 & 4826 & 5261 \\
\hline $285\left(\sigma_{5}\right)$ & 6097 & 7904 & 7051 \\
\hline $274\left(\sigma_{6}\right)$ & 11260 & 8958 & 10008 \\
\hline $263\left(\sigma_{7}\right)$ & & $10^{5}$ more & \\
\hline
\end{tabular}

The curve was obtained by fitting data with least square method as Fig. 3. The curve shows that the sample's life prolongs with the decrease of stress amplitude; the slope of curve augments with the increase of stress amplitude, which means the velocity of reduction of sample's life decreases with the increase of stress amplitude.

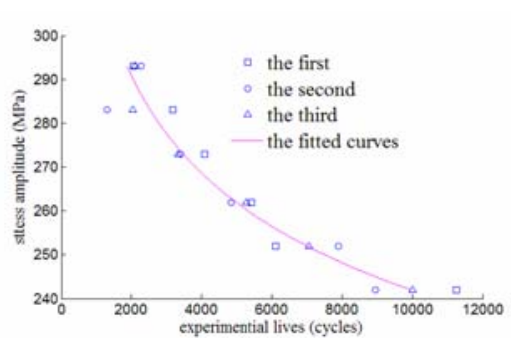

Figue 3. Stress-life

When sample's life is greater than $10^{3}$, power function is taken to depict $\mathrm{S}-\mathrm{N}$ carve as a way of mathematical expression[7-11].

$$
S^{m} \times N=C
$$

Where $\mathrm{m}$ and $\mathrm{C}$ are parameters relating to material, rate of stress, way of load.

It has been reported that when load frequency is less than $20 \mathrm{~Hz}$, it has little affection on sample's life. So the affection of load frequency can be ignored in this paper. Fitting data by power function, $\mathrm{m}$ and $\mathrm{C}$ were obtained:

$$
\begin{aligned}
& \mathrm{m}=8.8496 \\
& \mathrm{C}=1.3044 \times 10^{25}
\end{aligned}
$$

When stress rate $\mathrm{R}=-1$ and load frequency was less than $20 \mathrm{~Hz}$, the relationship between stress and life was expressed as the following:

$$
S^{8.8496} \times N=1.3044 \times 10^{25}
$$

From Eq. (2) the fatigue limit of $06 \mathrm{Cr} 19 \mathrm{Ni10}$ steel was calculated as $187.51 \mathrm{MPa}$. According to empirical formula, the fatigue limit of material was between $(0.3-0.45) \sigma_{\mathrm{b}}$. The calculated result was among the range of it. So it is practical to calculate the low fatigue life of $06 \mathrm{Cr} 19 \mathrm{Ni} 10$ steel based on Eq. (2).

The natural logarithm of Eq. (1) was taken:

$$
\lg S=A+B \lg N
$$

Where $\mathrm{A}=\operatorname{lgC} / \mathrm{m}, \mathrm{B}=-1 / \mathrm{m}$.

In accordance with Eq. (3), S-N double logarithmic curve should conform linear relation. The natural logarithm of test data can be taken and pointed on log-log coordinates as Fig. 4.

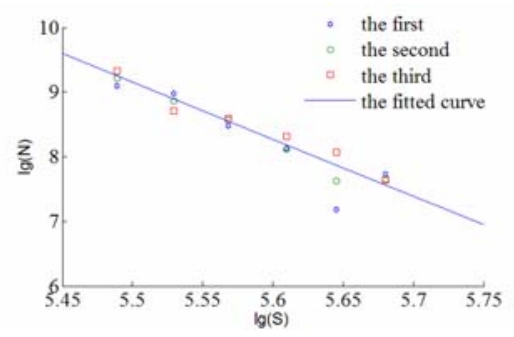

Figue 4. Double logarithmic curve of the stress-life

Fig. 4 shows that the points approach to a line, so the double logarithmic linear relation of stress and life is verified. 
Up and down experimental method was taken to measure the conditional fatigue limit of $06 \mathrm{Cr} 19 \mathrm{Ni10}$ steel[12]. From $\sigma_{1}$ to $\sigma_{5}$, the sample ruptured less than $10^{5}$ cycles; when $\sigma_{6}=242$ $\mathrm{MPa}$, the sample's life prolonged to $10^{5}$ cycles; when $\sigma_{7}=231$ $\mathrm{MPa}$, the sample didn't rupture in $10^{5}$ cycles and the difference of aforementioned two stresses was less than $5 \%$ of $\sigma_{7}$. So the average of $\sigma_{6}$ and $\sigma_{7}$ was the conditional fatigue limit:

$$
\sigma_{-1}=\frac{1}{2}\left(\sigma_{6}+\sigma_{7}\right)=236.5 \mathrm{MPa}
$$

\section{B. The relationship between strain and life}

Supposing a homogenous strain of gauge section in analysis of the relationship between strain and life, the strain was measured by a strain gauge[13]. Test data was fitted with least square method and the curves were shown in Fig. 5

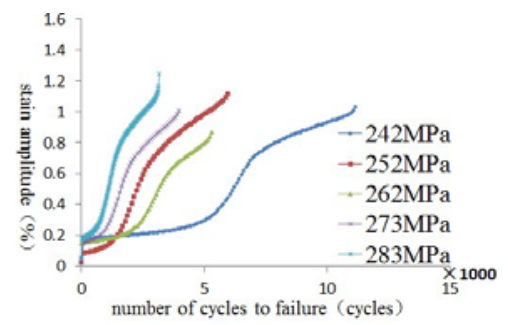

Figue 5. Strain-cycles curves of the different stress

Fig. 5 indicates that on the primary $1 / 3$ period of sample's life, strain increases with the augmentation of circulation times, but the magnitude of increase is little; when circulating times reach $1 / 3$, strain increase rapidly; when circulating times reach $1 / 2$, strain tends to be stable till the sample cracked, meanwhile, the real strain is greater when the stress amplitude is larger.

\section{The Relationship Between Life and Energy}

It is supposed that the energy of whole system in analyzing the relationship between life and energy complys with energy conservation, which means only the plastic strain energy was considerate and sample didn't produce heat energy itself. Energy in the text referred to plastic strain energy of one circulation week. Curve fitting testing data with least square method, the curves were shown in Fig. 6 :

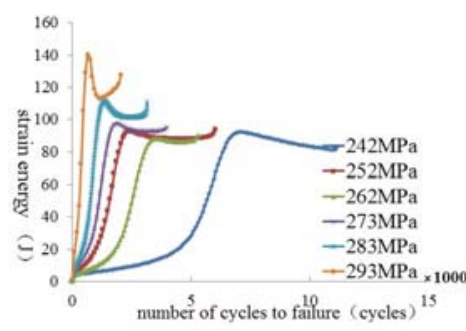

Figue 6. Energy-cycles Curves

Fig. 6 indicates that on the primary $1 / 3$ period of sample's life, the plastic strain energy increase rapidly with the increase of circulation times. When circulation times reach $1 / 3$ of whole life, the plastic strain energy comes to maximum and then decreases slightly and keeps stable; the plastic strain energy increases once again when the sample cracks. Other conditions also accorded with above regulation.
Having constant observation of test process under stress amplitude of $273 \mathrm{MPa}$, the number of cycles was recorded when the micro crack appears. The specimen total life and when strain energy came to the largest could be found by computer acquisition data (Table. 3 ).

\begin{tabular}{|c|c|c|c|}
\multicolumn{2}{c}{ TABLE III. } & \multicolumn{2}{c|}{ CYCLING TIMES } \\
\hline & first(cycle) & second(cycle) & third(cycle) \\
\hline micro crack & 1189 & 1065 & 1091 \\
\hline max energy & 1263 & 1190 & 1087 \\
\hline total life & 4087 & 3391 & 3339 \\
\hline
\end{tabular}

Table. 3 shows that when the micro cracks appear on the specimen surface, the number of cycles is one third of its total life. Table. 3 also shows that when there were micro cracks, plastic strain achieve maximum value, that is to say, when plastic strain reaches its maximum value, crack source would form on the surface.

\section{RESULTS AND ANALYSIS OF INCISION SAMPLE}

\section{A. Incision sample results}

Tests were carried out three times in each operating condition and the average value was obtained. The results were shown in Table. 4:

\begin{tabular}{|c|c|c|c|}
\hline TABL & INCISION & XPERI & DATA \\
\hline \multirow{2}{*}{ stress $(\mathrm{MPa})$} & \multicolumn{3}{|c|}{ notch depth $(\mathrm{mm})$} \\
\hline & 1.43 & 1.65 & 1.78 \\
\hline 230 & 1983 & 1440 & 1371 \\
\hline 219 & 2547 & 2376 & 2209 \\
\hline 208 & 4472 & 3310 & 3016 \\
\hline 197 & 7825 & 6249 & 5715 \\
\hline
\end{tabular}

The natural logarithm of the test data was taken and it was pointed on log-log coordinates. The curves were shown in Fig. 7:

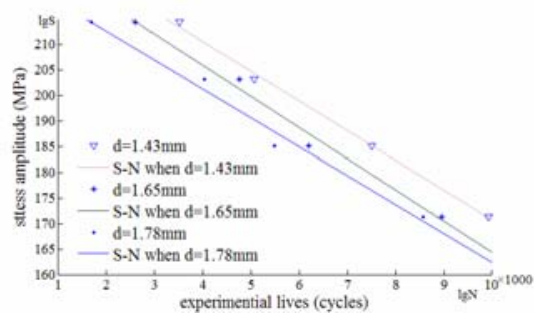

Figue 7. Notch S-N curve

Fitting the expressions as follows:

when $\mathrm{d}=1.43 \mathrm{~mm}$ :

$$
\begin{aligned}
& \mathrm{N}=500.8411 \times 5^{-0.4256} \\
& \mathbb{N}=485.4003 \times S^{-0.243} \\
& \mathrm{~N}=691.3532 \times \mathrm{S}^{-6.42 \% \mathrm{~F}}
\end{aligned}
$$

Fig. 7 indicates that experimental data tends to a line on $\log -\log$ coordinates and the slopes are approximately equal. 
Therefore the sample's life could be calculated when the depth of incision and the amplitudes of stress are foregone.

\section{B. The influence of stress amplitude on fatigue life}

Four different stress amplitudes were taken in fatigue tests, the largest of which was $0.35 \sigma_{\mathrm{b}}$ and the gap between two phases was $0.02 \sigma_{\mathrm{b}}$. Results were shown in Table. 3 .

Through the fitted formula and Fig. 7 the conclusion could be found that when sample's life is less than $10^{4}$ circles and there is a certain depth of notch, the life increase with the decrease of stress amplitude; Notch samples' stress has an exponential relation with fatigue life, that is to mean the decreasing velocity of fatigue life decrease with increase of stress amplitude; stress and life have a linear relationship at log-log coordinate.

\section{The influence of notch depth on fatigue life}

The influence of notch depth on fatigue life was studied through cutting different notch depth and circumferential notch on smooth sample in the article. The $d / D$ respectively were $0.13,0.15,0.17$. The results were shown on Table. 3 . And the curves were shown in Fig. 8:

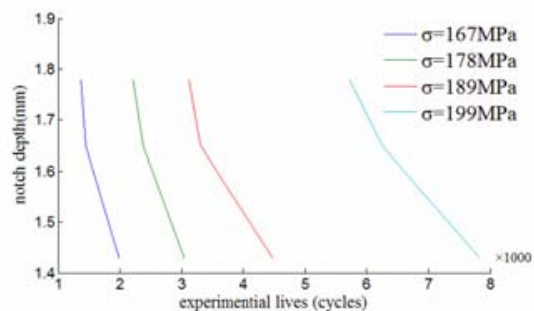

Figue 8. Relationship between depth and life

Fig. 8 shows that the deeper notch results in the shorter fatigue life; the curve of each stress consists of two segments. When the notch is deeper, the line slope is smaller, which means the depth of notch has smaller influence on sample life and the sensitivity of sample life to depth reduces.

\section{The influence of Incision Angle on fatigue life}

The different angel of incision was taken to study its influence on fatigue life. When the depth of incision $d=1.43 \mathrm{~mm}$, tip radius $r=0.3 \mathrm{~mm}, \sigma=167 \mathrm{MPa}$ and notch angel located at $30^{\circ}$, $45^{\circ}$ and $60^{\circ}$, the fatigue tests were carried out two times under each angel. The results were shown in Table. 5:

TABLE V. $\quad$ EXPERIMENTAL DATA OF DIFFERENT INCISION ANGLE

\begin{tabular}{|c|c|c|}
\hline notch angle( $\left.{ }^{\circ}\right)$ & first(cycle) & second(cycle) \\
\hline 30 & 7983 & 7691 \\
\hline 45 & 8012 & 7654 \\
\hline 60 & 7769 & 7834 \\
\hline
\end{tabular}

Plot the test data as Fig. 9.

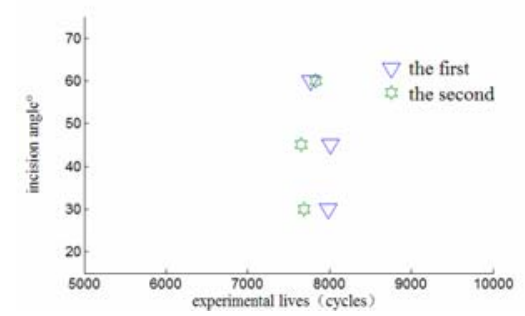

Figue 9. Relationship between angle and life

Fig. 9 shows that test figures of each time have little difference under $5 \%$ of total life. So it can be concluded that incision angels among $30^{\circ}-60^{\circ}$ has tiny influence to sample life and even it could be ignored.

\section{OBSERVATION OF SAMPLE FRACTURE}

The fatigue tests in the text belonged to low circle fatigue under controlled stress. Many crack originals existed in the fracture and the fatigue crack fully expanded. Therefore the fatigue expansion region was lager while instant rupture zone was small.

The sample's fracture image was magnified 25 times by Scanning Electron Microscope (Fig. 10). Part A is crack source area (a small area), Part B is crack growth area (about $2 / 3$ of fracture) and Part $C$ is transient breaking area (about $1 / 3$ of fracture) in the picture[14-15].

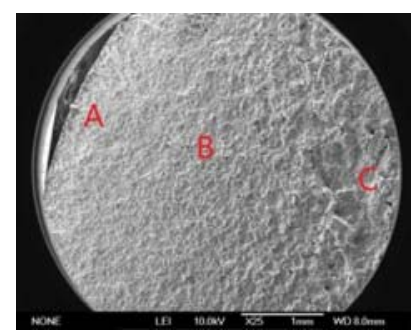

Figue 10. Fracture macro-morphology

\section{A. Analyses of smooth sample fracture}

Fatigue source area is considered the first period of crack initiation and stable propagation. Because of the different mechanism of fatigue crack initiation and fatigue crack propagation, the images of fatigue source area have significant difference under different conditions. The micro appearance of smooth sample's crack source in different stresses were shown in Fig. 11
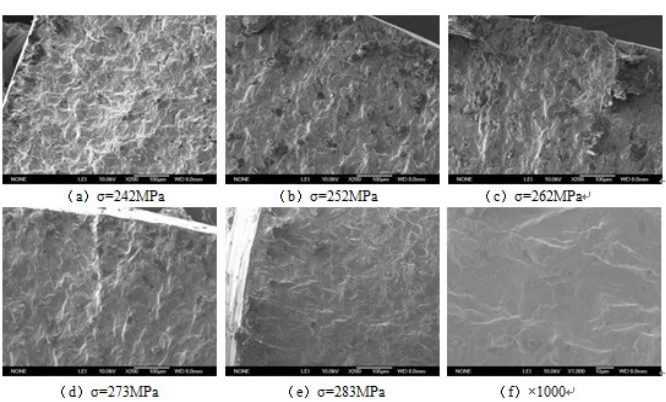

Figue 11. Crack initiation district morphology 
The clear crack sources cannot be observed from crack source area morphology, so it is impractical to judge the number of crack source and crack source spacing; few clear crack sources can be observed from Fig. 11(c); more crack sources appears in Fig. 11(d) and the spacing of crack source is shorted. Crack sources are obviously observed from Fig. 11(e), and the number of them is more. The morphology of crack source area is magnified 1000 times as shown in Fig. 11(f), and the crack source area is relatively flat.

The conclusion can be known that the higher level of load leads to more fatigue crack initiations which have little spacing, the shorter life as well as rougher fracture surface fatigue source area. The reasons are as following: higher level of load causes fatigue crack initiation more easily, so the number of crack increases, which resulted in generating creaks quickly and the fracture surface is rougher. Conversely a smaller load need more time to strand sample, which means more friction between fracture surfaces, so fracture surface is smother.

The main feature of crack propagation region is that fatigue striations appear on fracture surface which are fundamental basis to judge whether it is fatigue crack. Forms and morphology of fatigue striations are affected by many factors. It has been reported that the higher the material static tensile strength is, the harder the fatigue striations to appear; the high tenacity material produces fatigue striations easily.

06Cr19Ni10 steel is Austenitic stainless steel, which has high toughness, so the fatigue striation can be observed on its fracture clearly. On the other aspect, the load also affects fatigue striation, generally speaking, the higher the frequency of the load and the lower the stress amplitude is, the tinier the fatigue striation is and spacing is smaller. Fracture images under SEM were shown in Fig. 12:

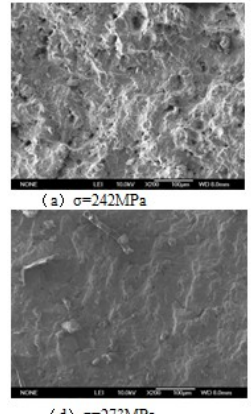

(d) $\sigma=273 \mathrm{MPa}$

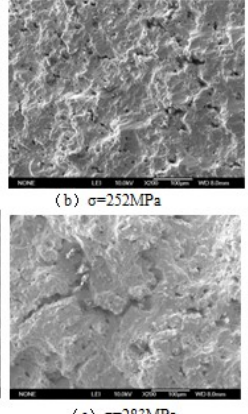

(e) $\sigma=283 \mathrm{MPa}$

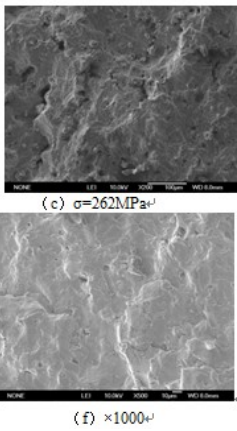

y
Fig.12 shows that the higher load is, the bigger spacing of fatigue striation is and the thicker the fatigue striation is.

The interruptions area is always mixed fracture. Micro appearance of main fracture is characteristic of static load interruptions as dimple fracture, sometimes quasi-cleavage fracture, cleavage fracture and intergranular fracture. All the fracture characteristics related to material and type of load.

Fig. 13 shows interruptions area morphology under different load and it appears as lacerated, dimple fracture; the larger the load is, the larger the transient fault zone area is and the rougher of the interruptions area is.

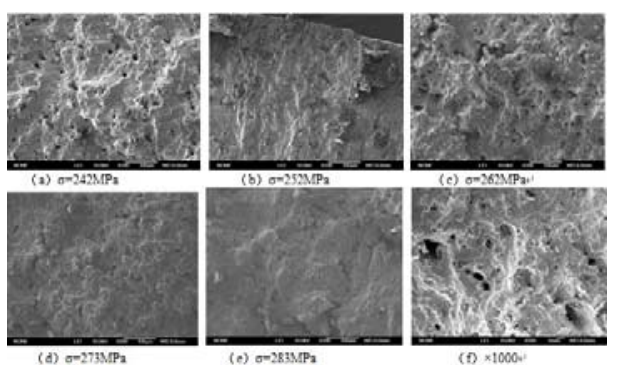

Figue 13. Blink district morphology

\section{B. Notched specimen fracture analysis}

Life of notched sample is shorter than smooth specimens. Stress concentration condition appears on the notch of notched specimen, which reduces specimen's fatigue life.
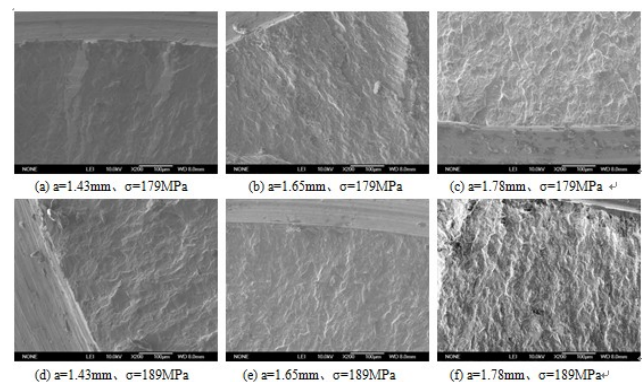

Figue 14. Crack initiation district morphology of incision specimens

Fig. 14 illustrates the crack source district morphology of incision specimens in different depth of notch. Fig. 14(a) shows crack source district morphology when depth of notch is $1.43 \mathrm{~mm}$ and $\sigma=179 \mathrm{MPa}$, which shows several crack sources and long distance between each other. Fig. 14(b) shows crack source district morphology when depth of notch is $1.43 \mathrm{~mm}$ and $\sigma=189 \mathrm{MPa}$, which shows more crack sources. Fig. 14(c) shows crack source district morphology when depth of notch is 1.65 $\mathrm{mm}$ and $\sigma=179 \mathrm{MPa}$ and Fig. 14(d) shows crack source district morphology when depth of notch is depth $=1.65 \mathrm{~mm}$ and $\sigma=189 \mathrm{MPa}$, which shows the latter have more crack sources than the former. Fig. 14(e) shows crack source district morphology when depth of notch is $1.87 \mathrm{~mm}$ and $\sigma=179 \mathrm{MPa}$ and Fig. 14(f) shows crack source district morphology when depth of notch is $1.87 \mathrm{~mm}$ and $\sigma=189 \mathrm{MPa}$, which shows the latter has more crack sources and shorter distance.

By comparing Fig. 14(a), (c) and (e), the number of crack sources increased with increasing stress. The same conclusion can be drawn by comparing Fig. 14(b), (d) and (f).
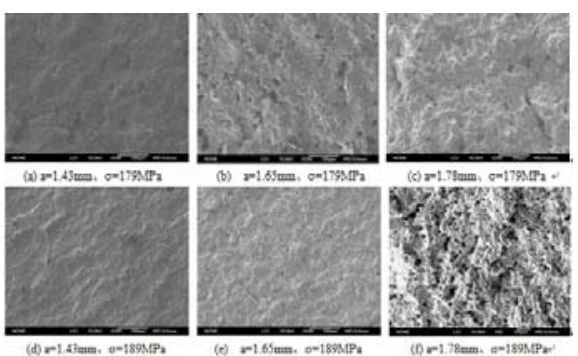

Figue 15. Crack propagation district morphology of incision specimens 
Through the observation of Fig. 15: there are many crack sources on crack source district which have more crack sources than smooth specimen. The deeper the depth is, the more crack sources have; the higher stress amplitude leads to more crack sources. The main reason is that the stress concentration on notch leads to generate crack sources easily, the more crack sources result in main crack easily, so the life of incision specimens is shorter than smooth specimens; the deeper the depth is, the more serious the stress concentration is. So the crack sources appear more easily, the specimens crack more quickly and the life of it is shorter[16].

The crack tip stress state and the level of the stress affected the formation and properties of fatigue striation. People considered the necessary condition of fatigue striation is that the crack tip is in open type plane state, thus only when the fatigue fracture and tensile stress is vertical, the fatigue striation would appear. The change of stress intensity factor range significantly affects the widths and spacing of fatigue striation.

The fatigue striation of crack propagation region on smooth specimens is always gibbose, while the incision specimen appears dished. Because incision specimens have serious stress concentration and the fatigue striation develops quickly on two sides, so it always appears dished (Fig. 15)

The rate of crack propagation affects life of specimens significantly. The different depths of notch lead to different width of fatigue striation. The deeper of the depth, the wider of fatigue striation and the quicker rate of crack propagation[17].

The blink district morphology of incision specimens and smooth specimens appear almost same which are lacerated and dimple fracture. The depth of notch and load affects the crack district morphology. The different depth of notch and stress concentration resulted in different speed of crack formation and propagation. The deeper the incision is, the lager the area of interruptions is and the rougher the fracture is; the bigger load results in the lager area of interruptions and the rougher fracture (Fig. 16).

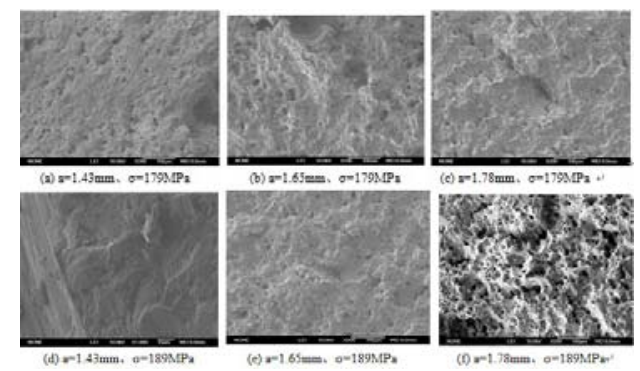

Figue 16. Blink district morphology of incision specimens

\section{CONCLUSION}

(1) By analyzing the test data, the conditional fatigue limit of $06 \mathrm{Cr} 19 \mathrm{Ni10}$ steel is got as $\sigma_{-1}\left(\mathrm{~N}=10^{5}\right) 236.5 \mathrm{MPa}$ and the life of specimens increase with the decrease of stress amplitude; the rate of life decrease decreases with the increase of stress amplitude.
(2) The total strain increases with the increase of stress amplitude; In a certain stress amplitude, strain increases gradually in cyclic process and it no longer increases when it reaches a certain value till the sample cracks at last.

(3)When micro cracks appear on the surface of specimens, plastic strain reaches to its maximum. When cycle times reach one third of total life, the crack source appears.

(4)There are many fatigue sources of low cycle fatigue and fracture morphology relates to stress amplitude. The higher level of the stress is, the more fatigue sources have, the wider of spacing of fatigue striation and the larger and rougher of the interruptions area.

\section{REFERENCES}

[1] Hu, Yan-Huil, Zhong, Qun-Peng. Effect of Ultrasonic Fatigue Testing Method on Fatigue Properties and Crack Initiation Mechanism of S06 Steel [J]. Journal of Materials Engineering, 2011,2:26-30

[2] HU Qiang, JIN Wei, LIU Xiaopeng, et al. Effect of Symmetric TensionCompresion Fatigue Controledo by Low stress/strain Amplitude on The Transformation Behavior of Ti49.6Ni Alloy. Acta Metallrugica Sinica. 2001,37(3):263-268

[3] Kanazawa, Miller K J, Brown M W. Low-cycle fatigue under out-ofphase load conditions[J]. Trans. ASME J. Engng Mater.Tech., 1977,99:222-228

[4] DING Jian, ZHANG Di, NISHIDA Shinichi. Study on Low Cycle Fatigue Proprety of Austenitic Strainless Steel Under Stress-controlled Conditon[J]. Acta Metallrugica Sinica,2002,38(12): :1261-1265

[5] Sergiy Shukayev, Oleksandr Zakhovayko, Timophiy Ponomarenko. Multiaxial Low Cycle Fatigue Life Prediction Criteria: Comparisons and Results[C]. Transactions of the 17th International Conference on Structural Mechanics in Reactor Technology (SMIRT 17), 2003

[6] Samuel K G. Evaluation of ageing-induced embrittlement in an austenitic strainless steel by instrumented impact testing[J]. Journal of Nuclear Materials, 1987, 150( 1) : 78-84.

[7] WEI Nan,JIN Yao,SUN Xunfang. Relationship of Cyclic Stress-strain and Damage for Low-cycle Fatigue[J]. Journal of Mechanical Strength. 2002, 24(3):426-428

[8] Bela I Sandor. Fundamentals of cycle stress and strain[M]. Science Press, Beijing: 1985

[9] Chung H M. Aging and life prediction of cast duplex strainless steel components[J]. International Journal of Pressure Vessels \&Piping, 1992, 50(1) : 179-213.

[10] YAO Changchun, LIANG Guiyuan, ZHANG Qinghua. Research on curves of cyclic stress-strain and definition of fracture life. Proc. of lst. National Conf. on Metal Fatigue[M], Metallurgy Industry Press, Beijing:1984

[11] WANG Bintuan, FAN Jianhua, YANG Qingxiong. Experimental research on material behavior of cyclic hardening and softening In Fatigue and Fracture[M], Aviation Industry Press, Beijing:1998

[12] Hassan T, Kyriakides S. Ratcheting of Cyclically Hardening and Softening Material: I: Uniaxial Behavior[C]. International Journal of Plasticity, 1994, 10:149-184.

[13] LIU Zhongxia, SONG Mousheng, LI Jiwen. Low-cycle Fatigue Behavior and Plastic Strain Energy of A356 Alloys[J]. The Chinese Journal of Nonferrous Metals, 2006,12(6):260-267

[14] Kwon J D, Woo S W, Lee Y S, et al. Thermal aging and low cycle fatigue characteristics of CF8M in a nuclear reactor coolant system[J]. Key Engineering Materials, 2000, 183-187(2) : 975-980.

[15] Basaran Cemal, Tang Hong, Nie Shihua. Experimental Damage Mechanics of Microelectronic Solder Joints Under Fatigue Load[C]. International Mechanical Engineering Congress and Exposition, 2002, 229-236

[16] Kwon J D, Woo S W, Lee Y S, et al. Effects of thermal aging on the low cycle fatigue behavior of austenitic-ferritic duplex cast strainless steel[J]. Nuclear Engineering and Design, 2001, 206(1) : 35-44.

[17] Nystrom M, Karlsson B. Fatigue of duplex strainless steel influence of discontinuous spinodally decomposed ferrite $[\mathrm{J}]$. Materials Science and Engineering A, 1996, 215(1) : 26-38 